\title{
Neurologic Findings Among Inpatients With COVID-19 at a Safety-net US Hospital
}

Pria Anand, MD, Lan Zhou, MD, Nahid Bhadelia, MD, Davidson H. Hamer, MD, David M. Greer, MD, and Anna M. Cervantes-Arslanian, MD

Correspondence

Dr. Anand

pria2@bu.edu

Neurology: Clinical Practice April 2021 vol. 11 no. 2 e83-e91 doi:10.1212/CPJ.0000000000001031

\section{Abstract}

\section{Objective}

To characterize the breadth of neurologic findings associated with severe acute respiratory syndrome coronavirus 2 (SARS-CoV-2) infection in a diverse group of inpatients at an urban, safety-net US medical center.

\section{Methods}

Patients were identified through an electronic medical record review from April 15, 2020, until July 1, 2020, at a large safety-net hospital in Boston, MA, caring primarily for underserved, lowincome, and elderly patients. All hospitalized adult patients with positive nasopharyngeal swab or respiratory PCR testing for SARS-CoV-2 during their hospitalization or in the 30 days before admission who received an inpatient neurologic or neurocritical care consultation or admission during the study period were enrolled.

\section{Results}

Seventy-four patients were identified ( $42 / 57 \%$ male, median age 64 years). The majority of patients self-identified as Black or African American (38,51\%). The most common neurologic symptoms at presentation to the hospital included altered mental status $(39,53 \%)$, fatigue (18, $24 \%)$, and headache $(18,18 \%)$. Fifteen patients had ischemic strokes $(20 \%)$. There were $10 \mathrm{in}$ hospital mortalities, with moderately severe disability among survivors at discharge (14\%, median modified Rankin Scale score of 4).

\section{Conclusions}

Neurologic findings spanned inflammatory, vascular pathologies, sequelae of critical illness and metabolic derangements, possible direct involvement of the nervous system by SARS-CoV-2, and exacerbation of underlying neurologic conditions, highlighting a broad range of possible etiologies of neurologic complications in patients with coronavirus disease 2019 (COVID-19). Further studies are needed to characterize the infectious and postinfectious neurologic complications of COVID-19 in diverse patient populations.

Since the first reported cases of pneumonia in December 2019, coronavirus disease 2019 (COVID-19) has rapidly become recognized as a multisystem illness, with known effects on virtually every organ system. ${ }^{1}$ Neurologic manifestations of COVID-19 are broad and may include seizures, ${ }^{2-4}$ movement disorders, ${ }^{5,6}$ peripheral neuropathies, ${ }^{7,8}$ cerebrovascular events, ${ }^{9-12}$ meningoencephalitis, ${ }^{13,14}$ posterior reversible encephalopathy syndrome, ${ }^{15-17}$ and other encephalopathies. ${ }^{18-20}$ These complications may result from direct invasion of the
MORE ONLINE

COVID-19 Resources

For the latest articles, invited commentaries, and blogs from physicians around the world

NPub.org/COVID19 
CNS by severe acute respiratory syndrome coronavirus 2 (SARS-CoV-2), as postinfectious complications, or as a result of critical illness and systemic infection. ${ }^{21,22}$

Although multiple case series have reported on individual neurologic complications such as ischemic stroke in small groups of patients with COVID-19, ${ }^{9,10}$ few have described the broad spectrum of neurologic disease across a large cohort of infected patients. ${ }^{22-25}$ Despite clear findings documenting the disproportionate impact of COVID-19 among both socioeconomically disadvantaged and racial and ethnic minority patient populations, ${ }^{26,27}$ few prior studies have characterized the full spectrum of neurologic complications of COVID-19 in a racially or socioeconomically diverse patient population. Here, we describe the breadth of neurologic findings associated with SARS-CoV-2 infection in a diverse group of inpatients at an urban, safety-net US academic medical center.

\section{Methods}

\section{Standard Protocol Approvals, Registrations, and Patient Consents}

The study protocol was approved by the Boston University Medical Campus Institutional Review Board, which waived participant consent given that this observational study was found to represent no more than minimal risk of harm.

\section{Setting}

This study was conducted on the inpatient services of Boston Medical Center (BMC), an academic safety-net medical center in Boston, MA. As the largest safety-net hospital in New England, over half of BMC's patients come from households making no more than $\$ 25,000$ annually, two-thirds identify as racial and/or ethnic minorities, and over one-third are born outside of the United States. Seventy-two percent of BMC's patient visits are made by underserved low-income and elderly patients who rely on government payors for insurance coverage. ${ }^{28}$ These government payors include both federal programs, such as Medicare and Medicaid, and state-specific programs, including Massachusetts' Health Safety Net program, which provides coverage for low-income individuals who are uninsured, underinsured, or ineligible for other insurance options because of their immigration status, and MassHealth, a Medicaid program that covers Massachusetts residents living at or below the federal poverty line, with special accommodations for pregnant women, minor children and their families, and individuals with chronic illnesses or disabilities. During the study period, Massachusetts was third among US states for both overall number of cases of COVID-19 and cases per capita, and BMC carried the secondhighest COVID-19 caseload in the state. ${ }^{29}$

\section{Patient Identification}

Patients were identified through a prospective review of the electronic medical record from April 15, 2020, until July 1, 2020. The study period was chosen based on the peak of new cases in the state of Massachusetts. ${ }^{30}$ All hospitalized patients with positive nasopharyngeal swab or respiratory PCR testing for SARS-CoV-2 during their hospitalization or in the 30 days before admission were eligible for inclusion. Those who received either (1) an inpatient neurologic or neurocritical care admission or (2) an inpatient neurologic or neurocritical care consultation at any time during the study period were included in the analysis.

\section{Data Collection and Variables}

Admission, hospitalization, and discharge variables were prospectively collected through a censoring date of July 1 , 2020. Variables of interest included demographic data, prior medical and neurologic history, presenting symptoms, disease severity, medications administered, imaging and electrographic findings, laboratory data, and clinical status. Final neurologic diagnoses were determined through a secondary review of the electronic medical records by a study neurologist. Stroke etiology was determined by a study stroke neurologist using the Trial of Org 10172 in Acute Stroke Treatment classification system. ${ }^{31}$ MRI obtained during the hospitalization was reviewed by a study neurologist for acute abnormalities. Clinical status was determined at the time of discharge, including in-hospital mortality. Modified Rankin Scale (mRS) scores were estimated for survivors before admission and at the time of discharge through review of the medical record by a study neurologist.

\section{Data Analysis}

All analyses were completed using Microsoft Excel. Patient characteristics were summarized by expressing categorical variables as counts and proportions and continuous variables as medians.

\section{Data Availability}

Anonymized data not published within this article will be made available by request from any qualified investigator.

\section{Results}

\section{Cohort Characteristics}

Nine hundred twenty-one adult patients were hospitalized with positive SARS-CoV-2 testing during the study period, of whom 74 had both positive SARS-CoV-2 testing and an inpatient neurologic or neurocritical care consultation or admission (42 male, 57\%) with a median age of 64 years at the time of hospitalization (range 23-94 years) (table 1). The majority of patients self-identified as Black or African American (38, 51\%) and 16 as Hispanic or Latino (22\%). Most patients were living at home before admission $(58,72 \%)$, with 8 who self-identified as unhoused or housing insecure before admission (11\%) and 13 admitted from a nursing facility (18\%). The majority of patients used public insurance options, including Medicare (25, $34 \%)$ and Medicaid, MassHealth, or the Health Safety Net program (31, 42\%). Medical history included vascular risk factors such as hypertension (43,58\%), atrial fibrillation (32, 
Table 1 Cohort Characteristics (April 15, 2020, to July 1 , 2020)

\begin{tabular}{ll}
\hline & $\mathrm{n}(\%)$ \\
\hline Sexal & $74(100)$ \\
\hline Male & \\
\hline Female & $42(57)$ \\
\hline Age at onset of symptoms, y & $32(43)$ \\
\hline $\mathbf{2 0 - 3 0}$ & \\
\hline $\mathbf{3 1 - 4 0}$ & $4(5)$ \\
\hline $\mathbf{4 1 - 5 0}$ & $8(11)$ \\
\hline $\mathbf{5 1 - 6 0}$ & $7(9)$ \\
\hline $\mathbf{6 1 - 7 0}$ & $12(16)$ \\
\hline $\mathbf{7 1 - 8 0}$ & $15(20)$ \\
\hline $\mathbf{8 1 - 9 0}$ & $20(27)$ \\
\hline $\mathbf{9 1 - 1 0 0}$ & $6(8)$ \\
\hline Race/ethnicity & $2(3)$ \\
\hline Black/African American & $13(18)$ \\
\hline Unknown/declined to answer & $1(1)$ \\
\hline Hispanic or Latino & $22(30)$ \\
\hline White & $16(22)$ \\
\hline Asian & $13(1)$ \\
\hline
\end{tabular}

Housing before admission

\begin{tabular}{ll}
\hline Living at home & $53(72)$ \\
\hline Nursing facility & $13(18)$ \\
\hline Unhoused or housing insecure & $8(11)$ \\
\hline Insurance & $31(42)$ \\
\hline $\begin{array}{l}\text { Medicaid, MassHealth, or the Health } \\
\text { Safety Net program }\end{array}$ & $25(34)$ \\
\hline Medicare & $17(23)$ \\
\hline Private insurance & $1(1)$ \\
\hline No insurance on file & $14.68-57.69$ \\
\hline Body mass index at admission & 28.97 \\
\hline Range & $27(36)$ \\
\hline Median & $24(32)$ \\
\hline Prior medical history & $32(43)$ \\
\hline Hypertension & $29(39)$ \\
\hline Atrial fibrillation & $27(58)$ \\
\hline Diabetes & \\
\hline Hyperlipidemia & \\
\hline Smoking & \\
\hline
\end{tabular}

Table 1 Cohort Characteristics (April 15, 2020, to July 1, 2020) (continued)

\begin{tabular}{ll}
\hline & $\mathrm{n}(\%)$ \\
\hline Chronic renal failure & $20(27)$ \\
\hline Asthma & $17(23)$ \\
\hline Coronary artery disease & $8(11)$ \\
\hline Prior thromboembolic event & $7(9)$ \\
\hline Sleep apnea & $5(7)$ \\
\hline
\end{tabular}

43\%), diabetes (29, 39\%), and hyperlipidemia (27, 36\%). Twenty patients had chronic kidney disease, including endstage renal disease (27\%).

\section{Clinical Data Associated With COVID-19}

The most common symptoms of COVID-19 on hospital presentation in our cohort were cough $(29,39 \%)$, dyspnea $(27,36 \%)$, and fever $(25,34 \%)$ (table 2). Eleven patients required intubation (15\%), whereas 28 required some form of supplemental oxygen (38\%). Thirty-four patients required intensive care (46\%). Medications used to treat COVID-19 included hydroxychloroquine $(28,38 \%)$, anakinra (12, $16 \%)$, sarilumab $(7,9 \%)$, tocilizumab $(3,4 \%)$, and remdesivir $(2,3 \%)$.

\section{Neurologic Symptoms and Diagnoses}

Neurologic diagnoses before admission included stroke (14, $19 \%)$, dementia (10, 14\%), and epilepsy (11,15\%) (table 3). The most common neurologic symptoms at presentation to the hospital included altered mental status $(39,53 \%)$, myalgia $(13,24 \%)$, fatigue $(18,24 \%)$, and headache $(18,18 \%)$. Multifactorial or toxic-metabolic encephalopathy was the most common diagnosis (26 patients, 35\%). Fourteen patients had ischemic strokes (19\%), including 6 from a cardioembolic source, 2 from small vessel occlusion, 4 strokes of undetermined etiology, and 2 strokes of other determined etiology in patients with known infectious endocarditis. One patient had a TIA or aborted stroke following thrombolysis. Seven patients had primary movement disorders (9\%), including 5 with myoclonus and 1 with osmotic demyelination syndrome.

\section{Imaging Findings}

Head CT was obtained in 33 cases (45\%). Brain MRI was obtained in 25 cases (31\%) and revealed acute abnormalities in 17 cases, including ischemic stroke in 7, cerebral venous sinus thrombosis in 2 , and intracranial hemorrhage in 3 . In 3 cases, imaging was suggestive of parainfectious inflammatory pathology (figure 1), including facial nerve enhancement in a patient who presented with bifacial nerve palsies, extensive T2-weighted changes in a patient with underling neuro-Behçet disease and concern for flare secondary to COVID-19, and T2-weighted parenchymal 
Table 2 Symptoms, Severity, and Treatment of Coronavirus Disease 2019 (COVID-19)

\begin{tabular}{|c|c|}
\hline & $\mathrm{n}(\%)$ \\
\hline \multicolumn{2}{|c|}{ Presenting symptoms of COVID-19 } \\
\hline Cough & $29(39)$ \\
\hline Dyspnea & $27(36)$ \\
\hline Fever & $25(34)$ \\
\hline Chest pain & $14(19)$ \\
\hline Chills & $13(18)$ \\
\hline Abdominal pain & $10(14)$ \\
\hline Vomiting & $9(12)$ \\
\hline Nausea & $8(11)$ \\
\hline Diarrhea & $7(9)$ \\
\hline Sore throat & $4(5)$ \\
\hline \multicolumn{2}{|l|}{ Respiratory severity } \\
\hline Room air & $36(49)$ \\
\hline Supplemental oxygen & $28(38)$ \\
\hline Intubation & $11(15)$ \\
\hline \multicolumn{2}{|l|}{ Location } \\
\hline Floor & $40(54)$ \\
\hline ICU & $34(46)$ \\
\hline \multicolumn{2}{|c|}{ Medications used for COVID-19 } \\
\hline None & $31(42)$ \\
\hline Hydroxychloroquine & $28(38)$ \\
\hline Anakinra & $12(16)$ \\
\hline Sarilumab & $7(9)$ \\
\hline Tocilizumab & $3(4)$ \\
\hline Remdesivir & $2(3)$ \\
\hline
\end{tabular}

changes and overlying leptomeningeal enhancement in a patient with seizures and concern for a parainfectious autoimmune encephalitis with improvement on subsequent imaging following corticosteroid administration. In 1 case, MRI revealed changes consistent with anoxic brain injury following cardiac arrest, and in 2 cases, MRI revealed changes consistent with posterior reversible leukoencephalopathy syndrome in critically ill patients (figure 2). The final case revealed extensive T2-weighted changes in a patient with underlying HIV infection and confirmed cryptococcal meningoencephalitis.

\section{Electrographic Findings}

EEG was completed in 11 cases (15\%). In 1 case, the EEG was in normal, whereas in 10 cases, abnormalities included epileptiform discharges, triphasic waves, slowing, and frontal intermittent rhythmic delta activity.

\section{CSF Analysis}

CSF was obtained in 9 cases (12\%) and revealed a pleocytosis (9 total nucleated cells $/ \mu \mathrm{L}$ ) and elevated protein $(72 \mathrm{mg} /$ $\mathrm{dL}$ ) in 1 case (an HIV-infected patient with cryptococcal meningoencephalitis) and an isolated elevated CSF protein $(82 \mathrm{mg} / \mathrm{dL})$ attributed to underlying diabetes mellitus in a second case (a patient with myoclonus).

\section{Prognosis}

There were 10 in-hospital mortalities within the cohort (14\%). Neurologic diagnoses among deceased patients included toxic-metabolic encephalopathy (3 patients), ischemic stroke (2), intracerebral hemorrhage (1), seizure (1), syncope (1), anoxic brain injury (1), and myoclonus (1). Cause of death in these patients included an upper gastrointestinal bleed in a patient who was anticoagulated for a deep vein thrombosis, a ruptured superior mesenteric artery aneurysm resulting in hemorrhagic shock in a patient with bacterial endocarditis, and multiorgan failure involving the kidneys, lungs, and heart in the remaining 8 patients. Six patients had transitioned to comfort measures based on their goals of care before death.

Among survivors, the median mRS score was 4, indicating moderately severe disability, from a preadmission $\mathrm{mRS}$ score of 2, indicating slight disability. Twenty-seven patients were discharged home with or without home health services (36\%), 20 to skilled nursing facilities (27\%, including 11 who had previously been living at home), 9 to acute rehabilitation (12\%, including 8 who had previously been living at home), and 3 to long-term acute care hospitals (4\%, including 2 had previously been living at home and 1 who was previously unhoused). Five patients were discharged to hospice, either at home or inpatient (7\%).

\section{Discussion}

Although neurologic complications of COVID-19 are described in the literature, existing publications focus on case reports and small series illustrating particular manifestations, with few large cohort studies. ${ }^{24,25,32}$ The largest previously published neurology-focused cohorts include 58 critically ill patients hospitalized in Strasbourg, France, and 153 patients with both neurologic and neuropsychiatric complications in a UK-wide surveillance study. ${ }^{24,25}$ No large US neurologic cohorts have been published in the literature, and despite robust data suggesting that both race and socioeconomic factors contribute to disparate rates of infection and prognoses, neither the French nor the British studies described the racial or socioeconomic makeup of their cohort. By contrast, we characterize neurologic findings in a racially and socioeconomically diverse cohort of patients with COVID-19.

The cohort described included a majority of patients who relied on government payors for insurance, including Medicaid, Medicare, MassHealth, and the Massachusetts Health 
Table 3 Neurologic Symptoms, Diagnoses, Testing, and Prognoses

\begin{tabular}{|c|c|}
\hline & n (\%) \\
\hline \multicolumn{2}{|l|}{ Prior neurologic diagnoses } \\
\hline Stroke & $14(19)$ \\
\hline Epilepsy & $11(15)$ \\
\hline Dementia & $10(14)$ \\
\hline Parkinson disease & $3(4)$ \\
\hline Traumatic brain injury & $3(4)$ \\
\hline Migraines & $2(3)$ \\
\hline Cerebral palsy & $1(1)$ \\
\hline Neuro-Behçet disease & $1(1)$ \\
\hline Multiple sclerosis & $1(1)$ \\
\hline Myasthenia gravis & $1(1)$ \\
\hline \multicolumn{2}{|l|}{ Neurologic symptoms at presentation } \\
\hline Altered mental status & $39(53)$ \\
\hline Myalgia & $18(24)$ \\
\hline Fatigue & $18(24)$ \\
\hline Headache & $13(18)$ \\
\hline Tremor & $7(9)$ \\
\hline Dizziness & $5(7)$ \\
\hline Gait instability & $3(4)$ \\
\hline Loss of consciousness & $3(4)$ \\
\hline Anosmia & $2(3)$ \\
\hline \multicolumn{2}{|l|}{ Final diagnosis } \\
\hline Toxic-metabolic encephalopathy & $26(35)$ \\
\hline Uremic encephalopathy & 7 \\
\hline Seizure & $15(20)$ \\
\hline Ischemic stroke & $15(20)$ \\
\hline Cardioembolic source & 6 \\
\hline Stroke of undetermined etiology & 4 \\
\hline Small-vessel occlusion & 2 \\
\hline \multicolumn{2}{|l|}{ Stroke of other determined etiology } \\
\hline Infectious endocarditis & 2 \\
\hline TIA & 1 \\
\hline Primary movement disorder & $7(9)$ \\
\hline Myoclonus & 5 \\
\hline Osmotic demyelination syndrome & 1 \\
\hline Tremor & 1 \\
\hline Peripheral neuropathy & $6(8)$ \\
\hline
\end{tabular}

Table 3 Neurologic Symptoms, Diagnoses, Testing, and Prognoses (continued)

\begin{tabular}{|c|c|}
\hline & n (\%) \\
\hline Hemorrhagic stroke & $3(4)$ \\
\hline Intraparenchymal hemorrhage & 1 \\
\hline Intraventricular hemorrhage & 1 \\
\hline Subarachnoid hemorrhage & 1 \\
\hline Functional neurologic disorder & $3(4)$ \\
\hline Primary headache & $3(4)$ \\
\hline Traumatic brain injury & $3(4)$ \\
\hline Cerebral venous sinus thrombosis & $2(3)$ \\
\hline $\begin{array}{l}\text { Posterior reversible encephalopathy } \\
\text { syndrome }\end{array}$ & $2(3)$ \\
\hline Vasovagal syncope & $2(3)$ \\
\hline Meningoencephalitis & $2(3)$ \\
\hline Anoxic brain injury & $1(1)$ \\
\hline \multicolumn{2}{|l|}{ MRI } \\
\hline Total performed & $23(31)$ \\
\hline Acute findings & 17 \\
\hline \multicolumn{2}{|l|}{ CSF } \\
\hline Total obtained & $9(12)$ \\
\hline Total nucleated cells: maximum, median & $9,1.5$ \\
\hline Total protein: maximum, median & $82,30.5$ \\
\hline \multicolumn{2}{|l|}{ EEG } \\
\hline Total performed & $11(15)$ \\
\hline Abnormal & 10 \\
\hline Slowing & 5 \\
\hline Epileptiform discharges & 2 \\
\hline Frontal intermittent rhythmic delta & 2 \\
\hline Triphasic waves & 1 \\
\hline $\begin{array}{l}\text { Median baseline mRS score (before } \\
\text { admission) }\end{array}$ & 2 (slight disability) \\
\hline \multicolumn{2}{|l|}{ Discharge location } \\
\hline Home without services & $22(30)$ \\
\hline Skilled nursing facility & $20(27)$ \\
\hline Deceased & $10(14)$ \\
\hline Acute rehab & $9(12)$ \\
\hline Home with services & $5(7)$ \\
\hline Inpatient hospice & $4(5)$ \\
\hline Long-term acute care hospital & $3(4)$ \\
\hline Home with hospice & $1(1)$ \\
\hline
\end{tabular}


Table 3 Neurologic Symptoms, Diagnoses, Testing, and Prognoses (continued)

$\mathrm{n}(\%)$

Median mRS score of survivors (at discharge) 4 (moderately severe disability)

Abbreviation: $\mathrm{mRS}=$ modified Rankin Scale.

Safety Net program. A majority of patients self-identified as Black or African American. A substantial minority of patients identified as unhoused or housing insecure before admission. These findings are consistent with a prior study of 2,729 patients with COVID-19 who were cared for in both the inpatient and outpatient settings at BMC, which found that nearly one-half were Black, approximately one-third were Hispanic, and 1 in 6 were experiencing homelessness. ${ }^{33}$

Neurologic findings spanned inflammatory complications (e.g., postinfectious bilateral Bell palsies, commonly known as Bell's palsies), vascular pathologies (e.g., ischemic stroke, intracerebral hemorrhage, and cerebral venous sinus thrombosis), sequelae of critical illness (e.g., anoxic brain injury and myoclonus), metabolic pathologies (e.g., uremic encephalopathy and osmotic demyelination syndrome), possible direct involvement of the nervous system by SARS-CoV-2 (e.g., a patient with pachymeningeal enhancement on brain MRI), and exacerbations of underlying neurologic conditions (e.g., a patient with underlying neuroBehçet disease with MRI findings suggestive of a flare in the setting of active COVID-19). Taken together, these findings demonstrate a broad range of etiologies of acute neurologic complications in patients with COVID-19. The majority of patients did not require critical care, suggesting that neurologic complications may be common in patients with moderate COVID-19 and those with severe disease.

Among those with postinfectious complications, 1 patient developed imaging findings and seizures concerning for an autoimmune encephalitis, with improvement in imaging following the administration of corticosteroids, a rarely described complication of COVID-19. ${ }^{34}$ CSF was obtained in just 9 cases, with an incidentally elevated protein in 1 case and elevated protein and nucleated cell count in a second case, an immunocompromised patient with an opportunistic, non-COVID meningoencephalitis. These findings are consistent with prior reports documenting unrevealing CSF protein and cell count findings in the setting of COVID-19, even in patients diagnosed with an infectious or parainfectious encephalitis and in patients with positive CSF testing for SARS-CoV-2. ${ }^{13,14,24,35}$ However, published data are limited, and further studies are needed to elucidate the significance of these findings.

Among patients with ischemic stroke, cardioembolic strokes were most common. Although infrequently reported in prior

Figure 1 Range of Inflammatory Imaging Findings in Patients With Coronavirus Disease 2019

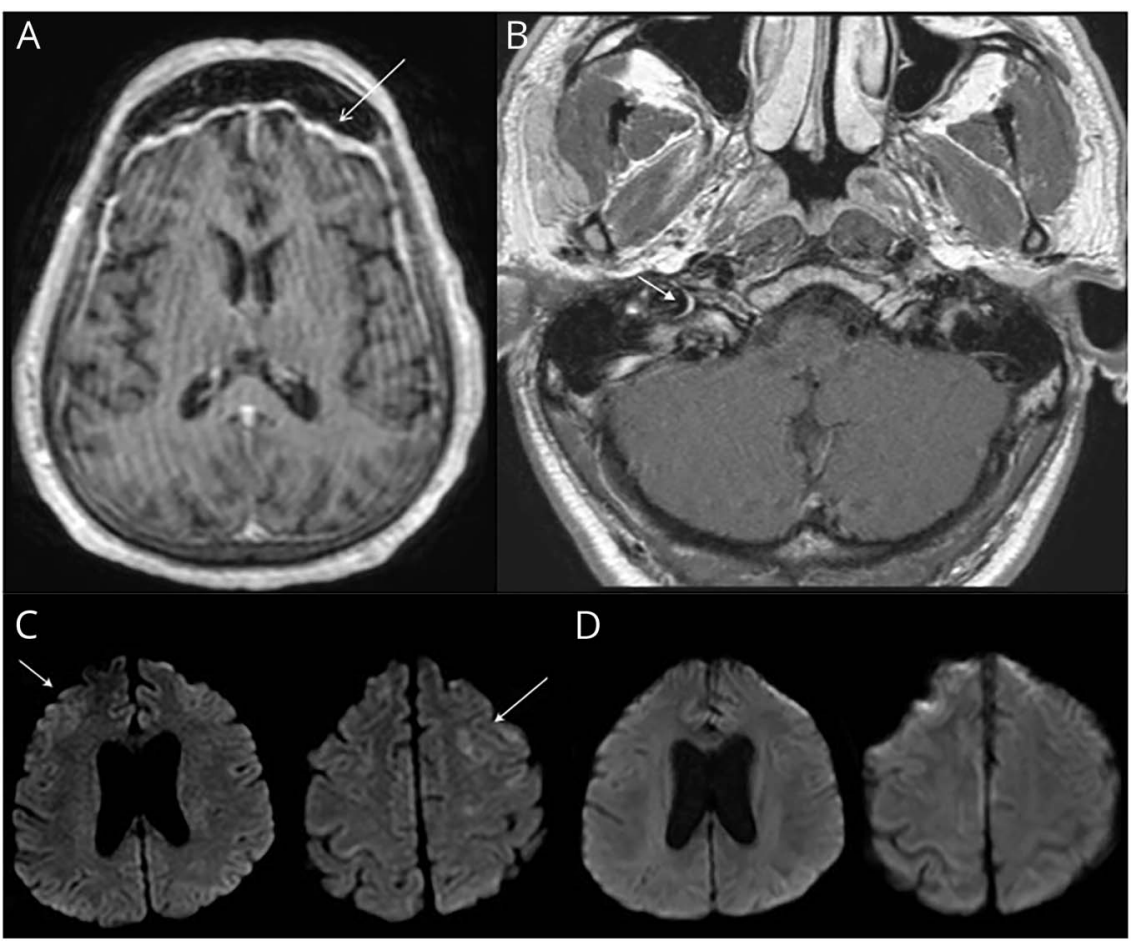

(A) Postgadolinium T1-weighted MRI sequences demonstrate diffuse smooth pachymeningeal thickening and enhancement most prominent in the frontal and temporal lobes. (B) Postgadolinium T1-weighted MRI sequences revea asymmetric enhancement of the labyrinthine segment and genu of the right facial nerve. (C) T2-weighted fluid-attenuated inversion recovery MRI sequences demonstrate hyperintensity of the bilateral frontal lobes that (D) resolved 3 weeks later following the administration of corticosteroids. 


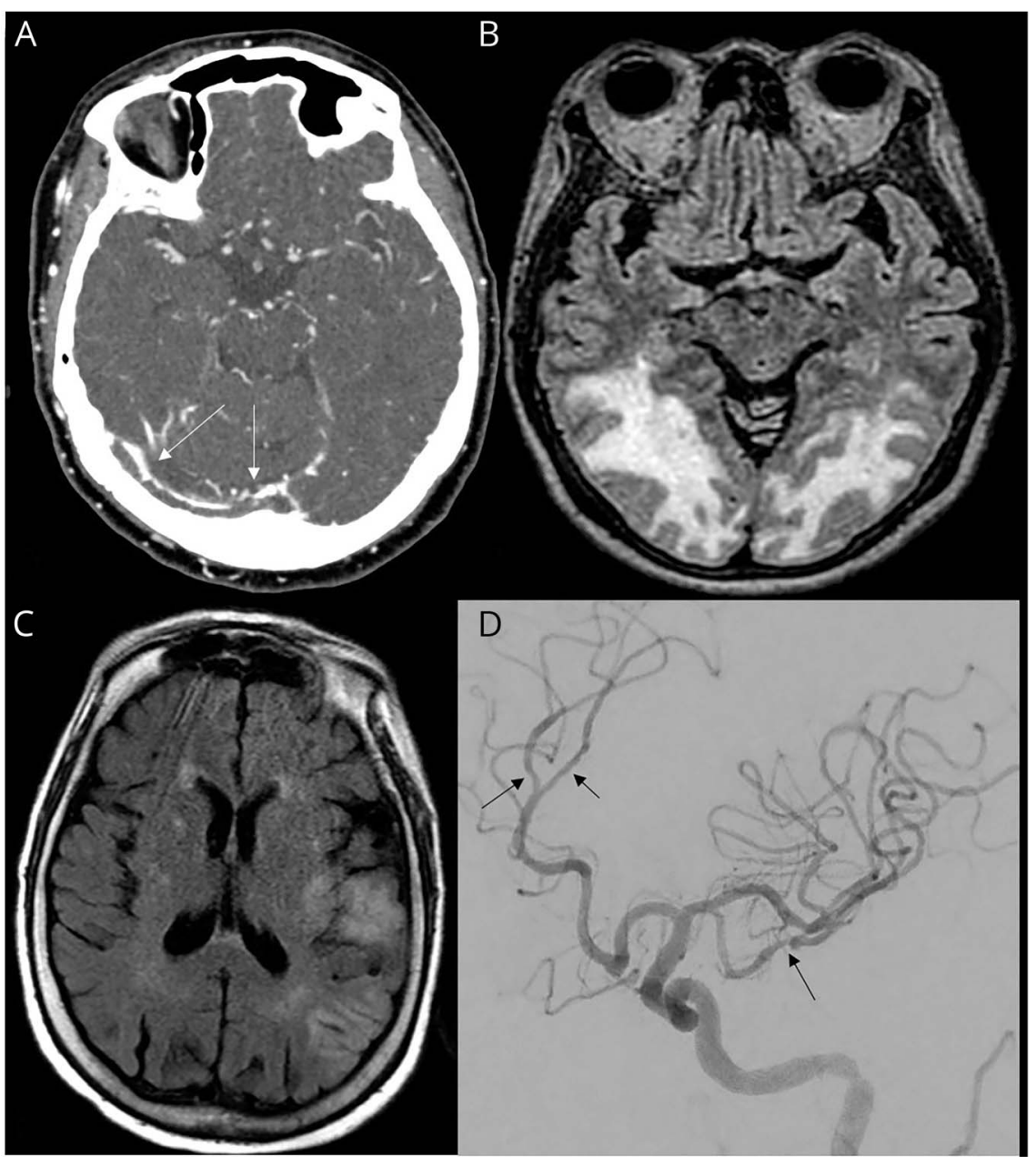

(A) CT venogram showing extensive thrombosis of cerebral venous sinuses (arrows: right transverse sinus clot extending into the torcula herophiles). (B) T2-weighted fluid-attenuated inversion recovery (FLAIR) MRI sequences demonstrate symmetric, confluent white matter abnormalities in the parieto-occipital lobes consistent with posterior reversible encephalopathy syndrome. (C) T2-weighted FLAIR MRI sequences with patchy infarcts within the left middle cerebral artery (MCA) territory. (D) Digital subtraction angiography showing diffuse vasculopathy of the $\mathrm{M} 2$ and $\mathrm{M} 3$ divisions of MCA and left pericallosal artery. literature regarding COVID-19, 5,6 movement disorders were also common, with mechanisms ranging from metabolic derangements in a patient who developed osmotic demyelination syndrome with parkinsonian features to anoxic injury in a patient with myoclonus. Three patients presented with traumatic brain injuries following falls at home, highlighting the risk of neurologic injury in the setting of inadequate social support and isolation, even in the setting of mild SARS-CoV-2 infection.

Prognoses were variable, with an in-hospital mortality rate of $14 \%$, higher than previously published in-hospital mortality rates in diverse non-neurologic inpatient cohorts. ${ }^{36}$ Patients who survived to discharge had moderately severe disability from a preadmission baseline of mild disability; however, the majority of patients were able to be discharged home with or without home health services.

We acknowledge several limitations to our study. It is possible that some patients with neurologic complications were not evaluated by or admitted to the neurology or neurocritical care services and therefore were not included in the analysis. This may have included patients with mild neurologic symptoms who did not require subspecialty care and critically ill patients who were intubated, sedated, or paralyzed with a limited neurologic examination or otherwise poor prognosis. Because of the observational nature of this study, ancillary testing was not standardized across all patients, with variable investigations performed. Finally, the focus of this study was on acute neurologic findings in hospitalized patients, without analysis of posthospital complications or mortality.

Prior studies have unequivocally demonstrated that the infection rates, morbidity, and mortality associated with COVID19 are affected by long-standing socioeconomic and racial disparities, which often affect health care access and utilization, underlying medical conditions, and employment and housing circumstances. $^{33}$ Because of the sample size of our study and the small number of patients affected by each individual neurologic finding, we were unable to assess for statistically significant associations between these critical factors and 
TAKE-HOME POINTS

$\rightarrow$ A broad range of etiologies of acute neurologic complications can be seen in patients with COVID19.

$\rightarrow$ Acute neurologic complications of COVID-19 may include parainfectious inflammatory diseases, vascular pathologies, sequelae of critical illness, metabolic disorders, possible direct involvement of the nervous system by SARS-CoV-2, and exacerbations of underlying neurologic conditions.

$\rightarrow$ Further studies are needed to fully understand the breadth of neurologic findings associated with SARS-CoV-2 infection in diverse patient populations given the disparate impact of COVID-19.

neurologic prognosis. However, our findings reflect the neurologic experiences of an urban, safety-net US medical center caring for a socioeconomically and racially diverse patient population at high risk of adverse health outcomes, particularly in the setting of COVID-19, an experience that has not been represented in the literature to date. Future studies may explore whether factors such as housing security, access to primary care, or insurance status may be protective against neurologic complications of COVID-19.

Further studies are needed to fully understand the unique neurologic risk profile of this vulnerable patient population given the disparate impact of COVID-19. These include larger, multicenter studies to characterize both the impact of health care disparities on the frequency and severity of specific neurologic complications of COVID-19 and the impact of underlying neurologic conditions and other medical comorbidities on patient outcomes after COVID-19. Planned studies at our center include a prospective study to characterize long-term neurologic sequelae among both hospitalized and ambulatory survivors of COVID-19 to determine whether illness severity, demographic and socioeconomic differences, immunologic profiles, comorbidities, or other underlying factors either predispose to or protect against neurologic complications, with the goal of leveraging these findings for early identification and preventive measures for those patients at highest risk.

\section{Study Funding}

This work is supported by a Simon Grinspoon Research Grant (P. Anand).

\section{Disclosure}

The authors report no disclosures. Full disclosure form information provided by the authors is available with the full text of this article at Neurology.org/cp.

\section{Publication History}

Received by Neurology: Clinical Practice August 12, 2020. Accepted in final form November 2, 2020.

Appendix Authors

\begin{tabular}{|c|c|c|}
\hline Author & Location & Contribution \\
\hline Pria Anand, MD & $\begin{array}{l}\text { Boston University } \\
\text { School of Medicine, MA }\end{array}$ & $\begin{array}{l}\text { Design and } \\
\text { conceptualization of the } \\
\text { study; collection and } \\
\text { analysis of data; and } \\
\text { drafted the manuscript } \\
\text { for intellectual content }\end{array}$ \\
\hline Lan Zhou, MD & $\begin{array}{l}\text { Boston University } \\
\text { School of Medicine, MA }\end{array}$ & $\begin{array}{l}\text { Revision of the } \\
\text { manuscript for } \\
\text { intellectual content }\end{array}$ \\
\hline $\begin{array}{l}\text { Nahid Bhadelia, } \\
\text { MD }\end{array}$ & $\begin{array}{l}\text { Boston University } \\
\text { School of Medicine, MA }\end{array}$ & $\begin{array}{l}\text { Revision of the } \\
\text { manuscript for } \\
\text { intellectual content }\end{array}$ \\
\hline $\begin{array}{l}\text { Davidson H. } \\
\text { Hamer, MD }\end{array}$ & $\begin{array}{l}\text { Boston University } \\
\text { School of Medicine, MA }\end{array}$ & $\begin{array}{l}\text { Revision of the } \\
\text { manuscript for } \\
\text { intellectual content }\end{array}$ \\
\hline David M. Greer, MD & $\begin{array}{l}\text { Boston University } \\
\text { School of Medicine, MA }\end{array}$ & $\begin{array}{l}\text { Revision of the } \\
\text { manuscript for } \\
\text { intellectual content }\end{array}$ \\
\hline $\begin{array}{l}\text { Anna M. Cervantes- } \\
\text { Arslanian, MD }\end{array}$ & $\begin{array}{l}\text { Boston University } \\
\text { School of Medicine, MA }\end{array}$ & $\begin{array}{l}\text { Collection and analysis of } \\
\text { data and revision of the } \\
\text { manuscript for } \\
\text { intellectual content }\end{array}$ \\
\hline
\end{tabular}

\section{References}

1. Greenland JR, Michelow MD, Wang L, London MJ. COVID-19 infection: implications for perioperative and critical care physicians. Anesthesiology 2020;132 1346-1361.

2. Asadi-Pooya AA. Seizures associated with coronavirus infections. Seizure 2020;79:49-52.

3. Lu L, Xiong W, Liu D, et al. New onset acute symptomatic seizure and risk factors in coronavirus disease 2019: a retrospective multicenter study. Epilepsia 2020;61:e49-e53.

4. Anand P, Al-Faraj A, Sader E, et al. Seizure as the presenting symptom of COVID-19. Epilepsy Behav 2020;112:107335.

5. Anand P, Zakaria A, Benameur K, et al. Myoclonus in patients with COVID-19: multicenter case series. Crit Care Med 2020;48:1664-1669.

6. Rábano-Suárez P, Bermejo-Guerrero L, Méndez-Guerrero A, et al. Generalized myoclonus in COVID-19. Neurology 2020;95:e767-e772.

7. Alberti P, Beretta S, Piatti M, et al. Guillain-Barré syndrome related to COVID-19 infection. Neurol Neuroimmunol Neuroinflamm 2020;7:e741.

8. Zhao H, Shen D, Zhou H, Liu J, Chen S. Guillain-Barré syndrome associated with SARS-CoV-2 infection: causality or coincidence? Lancet Neurol 2020;19:383-384.

9. Beyrouti R, Adams ME, Benjamin L, et al. Characteristics of ischaemic stroke associated with COVID-19. J Neurol Neurosurg Psychiatry 2020;91:889-891.

10. Oxley TJ, Mocco J, Majidi S, et al. Large-vessel stroke as a presenting feature of COVID-19 in the young. N Engl J Med 2020;382:e60.

11. Carneiro T, Dashkoff J, Leung LY, et al. Intravenous tPA for acute ischemic stroke in patients with COVID-19. J Stroke Cerebrovasc Dis 2020;29:105201.

12. Hughes C, Nichols T, Pike M, Subbe C, Elghenzai S. Cerebral venous sinus thrombosis as a presentation of COVID-19. Eur J Case Rep Intern Med 2020;7:001691.

13. Ye M, Ren Y, LT. Encephalitis as a clinical manifestation of COVID-19. Brain Behav Immun 2020;88:945-946.

14. Moriguchi T, Harii N, Goto J, et al. A first case of meningitis/encephalitis associated with SARS-coronavirus-2. Int J Infect Dis 2020;94:55-58.

15. Anand P, Lau KHV, Chung DY, et al. Posterior reversible encephalopathy syndrome in patients with coronavirus disease 2019: two cases and a review of the literature. J Stroke Cerebrovasc Dis 2020;29:105212.

16. Princiotta Cariddi L, Tabaee Damavandi P, Carimati F, et al. Reversible encephalopathy syndrome (PRES) in a COVID-19 patient. J Neurol 2020;267:3157-3160.

17. Kaya Y, Kara S, Akinci C, Kocaman AS. Transient cortical blindness in COVID-19 pneumonia; a PRES-like syndrome: case report. J Neurol Sci 2020;413:116858.

18. Haddad S, Tayyar R, Risch L, et al. Encephalopathy and seizure activity in a COVID19 well controlled HIV patient. IDCases 2020;21:e00814.

19. Poyiadji N, Shahin G, Noujaim D, Stone M, Patel S, Griffith B. COVID-19-associated acute hemorrhagic necrotizing encephalopathy: CT and MRI features. Radiology 2020;296:e120. 
Franceschi AM, Ahmed O, Giliberto L, Castillo M. Hemorrhagic posterior reversible encephalopathy syndrome as a manifestation of COVID-19 infection. Am J Neuroradiol 2020;41:1173-1176

21. Koralnik IJ, Tyler KL. COVID-19: a global threat to the nervous system. Ann Neurol 2020;88:1-11.

22. Mao L, Jin H, Wang M, et al. Neurologic manifestations of hospitalized patients with coronavirus disease 2019 in Wuhan, China. JAMA Neurol 2020;77:683-690.

23. Ellul MA, Benjamin L, Singh B, et al. Neurological associations of COVID-19. Lance Neurol 2020;19:767-783.

24. Helms J, Kremer S, Merdji H, et al. Neurologic features in severe SARS-COV-2 infection. N Engl J Med 2020;382:2268-2270.

25. Varatharaj A, Thomas N, Ellul MA, et al. Neurological and neuropsychiatric com plications of COVID-19 in 153 patients: a UK-wide surveillance study. Lancet Psychiatry 2020;7:875-882

26. Yaya S, Yeboah $\mathrm{H}$, Charles $\mathrm{CH}$, Otu A, Labonte R. Ethnic and racial disparities in COVID-19-related deaths: counting the trees, hiding the forest. BMJ Glob Health 2020;5:e002913.

27. Baqui P, Bica I, Marra V, Ercole A, van der Schaar M. Ethnic and regional variations in hospital mortality from COVID-19 in Brazil: a cross-sectional observational study. Lancet Glob Health 2020;8:e1018-e1026.

28. Boston Medical Center. Boston Medical Center Homepage. 2020.
29. Centers for Disease Control and Prevention (CDC). Coronavirus Disease 2019 (COVID-19) Cases in the United States. Atlanta: CDC COVID Data Tracker; 2020.

30. CDC. Trends in Number of COVID-19 Cases in the US Reported to CDC, by State/ Territory. Atlanta: CDC COVID Data Tracker; 2020.

31. H PAdams J, EMarsh E III. Classification of subtype of acute ischemic stroke. Definitions for use in a multicenter clinical trial. TOAST. Trial of Org 10172 in Acute Stroke Treatment. Stroke 1993;24:35-41.

32. Ferrarese C, Silani V, Priori A, et al. An Italian multicenter retrospective-prospective observational study on neurological manifestations of COVID-19 (NEUROCOVID). Neurol Sci 2020;41:1355-1359.

33. Hsu HE, Ashe EM, Silverstein M, et al. Race/ethnicity, underlying medical conditions, homelessness, and hospitalization status of adult patients with COVID-19 at an urban safety-net medical center-Boston, Massachusetts, 2020. MMWR Morb Mortal Wkly Rep 2020;69:864-869.

34. Pilotto A, Odolini S, Masciocchi S, et al. Steroid-responsive encephalitis in coronavirus disease 2019. Ann Neurol 2020;88:423-427.

35. Pugin D, Vargas MI, Thieffry C, et al. COVID-19-related encephalopathy responsive to high doses glucocorticoids. Neurology 2020;95:543-546.

36. Gold JAW, Wong KK, Szablewski CM, et al. Characteristics and clinical outcomes of adult patients hospitalized with COVID-19-Georgia, March 2020. MMWR Morb Mortal Wkly Rep 2020;69:545-550. 


\section{Neurology ${ }^{\circ}$ Clinical Practice}

\section{Neurologic Findings Among Inpatients With COVID-19 at a Safety-net US Hospital}

Pria Anand, Lan Zhou, Nahid Bhadelia, et al.

Neurol Clin Pract 2021;11;e83-e91 Published Online before print December 9, 2020

DOI 10.1212/CPJ.0000000000001031

This information is current as of December 9, 2020

\section{Updated Information \& Services}

References

Subspecialty Collections

Permissions \& Licensing

Reprints including high resolution figures, can be found at: http://cp.neurology.org/content/11/2/e83.full.html

This article cites 33 articles, 5 of which you can access for free at: http://cp.neurology.org/content/11/2/e83.full.html\#\#ref-list-1

This article, along with others on similar topics, appears in the following collection(s):

All Cerebrovascular disease/Stroke

http://cp.neurology.org//cgi/collection/all_cerebrovascular_disease_str oke

All Epilepsy/Seizures

http://cp.neurology.org//cgi/collection/all_epilepsy_seizures COVID-19

http://cp.neurology.org//cgi/collection/covid_19

Health disparities

http://cp.neurology.org//cgi/collection/health_disparities

Inclusion, Diversity, Equity, Anti-racism, and Social Justice

(IDEAS)

http://cp.neurology.org//cgi/collection/all_equity_diversity_and_inclusi on

Structural and social determinants of health

http://cp.neurology.org//cgi/collection/structural_social_determinants

Information about reproducing this article in parts (figures,tables) or in its entirety can be found online at:

http://cp.neurology.org/misc/about.xhtml\#permissions

Information about ordering reprints can be found online:

http://cp.neurology.org/misc/addir.xhtml\#reprintsus

Neurol Clin Pract is an official journal of the American Academy of Neurology. Published continuously since 2011, it is now a bimonthly with 6 issues per year. Copyright ( 2020 American Academy of Neurology. All rights reserved. Print ISSN: 2163-0402. Online ISSN: 2163-0933.

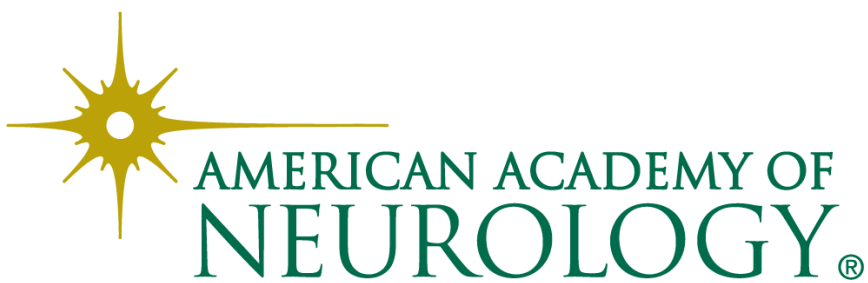

